\title{
Women in German neurosurgery: status and representation at annual national meetings
}

\author{
Elisabeth Ronne-Engström ${ }^{1}$ (D)
}

Received: 6 December 2019 / Accepted: 10 December 2019 /Published online: 20 December 2019

(C) Springer-Verlag GmbH Austria, part of Springer Nature 2019

The present article [2] shows a low female representation in neurosurgery in Germany, and also that the gender distribution was uneven between the neurosurgical subspecialties. Sweden has similar results; in 2017, $45 \%$ of all certified physicians were women, but there was an obvious difference in gender distribution between different specialties. Vascular surgery, thoracic surgery, and neurosurgery had the lowest representation of female certified specialists with 12,13 , and $16 \%$, respectively. Pediatric psychiatry, gynecology, and school health service had the highest with 73, 69, and 67\%, respectively [4]. It is well known that there is a gender gap in the labor market [1], with a majority of women in professions traditionally considered female and a majority of men in professions considered to be male. It is possible that we see this gender gap also in medicine, with certain medical areas considered to be female and other male. This is not necessarily due to discrimination. There could be differences between women and men resulting in greater interest and competence in different areas. However, when the effects for women are lower salary, less prestige and influence, fewer research opportunities, and a need to work part time due to failing social structures, then the uneven gender distribution have a discriminatory effect.

An important result in the article is that they found that relatively fewer women than men were members of the German Neurosurgical Society. Societies like this are important places for networking and provide opportunities to influence the development of the field. Both women and men should engage in this for their own good, especially the young physicians since they are our future. Equally important are the conference meetings. These are platforms for improving clinical care and for personal profiling. The authors showed that women had shorter presentation times and were

This article is part of the Topical Collection on Neurosurgery general

Elisabeth Ronne-Engström

Elisabeth.ronne.engstrom@akademiska.se

1 Department of Neuroscience, Neurosurgery, Uppsala University Hospital, 75185 Uppsala, Sweden underrepresented in organizing committees as well as for invited key-note lectures in these conferences. This could have a generational explanation. One could suspect that the older and more experienced generation is predominantly male, and that the younger generation is more mixed. It is now up to Germany to support these young women and men and give them equal possibilities for development. In order to do this, in Germany and all other countries, the gender distribution has to be monitored. Uneven distributions should be analyzed on a regular basis regarding mechanisms and consequences. Ideally, the distribution of neurosurgeons should be mirrored in all levels, e.g. clinical positions, members of the society, board positions, and number of researchers. Monitoring of gender distribution should also include salaries, extra work benefits, and time for parental leave. Many countries already have good structures available for this, see, e.g. Statistics Norway's indicators for monitoring gender equality [3].

So what can be done about inequality? The authors suggest structured programs to support gender equality. This could include frameworks for reviews of grants and clinical positions, that also include that when applications are considered to be equal, the gender in minority is favored. This could result in a more equal situation on a long-term basis. Sometimes, there are suggestions for starting a society for women in neurosurgery. I personally think that this would be a mistake; it would just confirm that female neurosurgeons are something other than "real" neurosurgeons. Gender inequality is not a problem that just exists within medicine. It is a larger problem created by habits, attitudes, and conditions in civil society. It is not something that just concerns women. Difficulties in balancing work and private life are the primary cause for different outcomes for women and men in the labor market (for references see [1]). This dilemma faces men as well as women, and young male residents sometimes regretfully conclude that they cannot combine family life with their career. This is fortunately changing in Sweden, where today, parental leaves are common for 
all young parents. Probably, many such social adjustments will be necessary to achieve equivalent conditions for men and women in our societies.

\section{References}

1. Castellano R, Rocca A (2019) Analyzing the gender gap in European markets at the NUTS-1 level. Congent Social Sciences:1595294
2. Lawson Mac Lean A (2020) Women in German neurosurgery: status and representation at annual meetings. Acta Neurochir

3. Statistics Norway (2017) Gender-divided labour market. www.ssb. no/en/befolkning/artikler-og-publikasjoner/gender-divided-labourmarket. Accessed 2019-12-06

4. Swedish National Board of Health and Welfare (2019) Statistikdatabas för hälso- och sjukvårdspersonal (swedish). https:// sdb.socialstyrelsen.se/if_per/val.aspx. Accessed 2019-12-06

Publisher's note Springer Nature remains neutral with regard to jurisdictional claims in published maps and institutional affiliations. 